\title{
BIENES Y DERECHOS REALES
}

Jaime Alcalde Silva*

LA INDIVIDUALIZACIÓN DEL BIEN RAÍZ QUE SE REIVINDICA

Y EL SEÑALAMIENTO REGISTRAL DE SUS LINDEROS

Corte Suprema, sentencia de 13 de agosto de 2020, Rol N..$^{\circ}$ 5837-2019, WESTLAW CL/JUR/76099/2020

THE SPECIFICATION OF THE REAL STATE WHICH OWNERSHIP IS CLAIMED AND THE EXPRESSION OF ITS BOUNDARIES IN THE LAND REGISTRY

\section{RESUMEN}

La Corte Suprema acogió un recurso de casación en el fondo, por estimar que el retazo de terreno que se reivindicaba estaba suficientemente individualizado con el croquis acompañado por el demandante y preparado por un ingeniero agrimensor. Ese dibujo había sido confeccionado a partir de los deslindes señalados en la inscripción conservatoria, y el levantamiento fue corroborado en el lugar al efectuar la inspección personal del tribunal. La utilización de varas como medida para delimitar los linderos no obsta a la correcta singularización del inmueble reclamado.

Palabras claves: reivindicación; demarcación; deslindes; sistema métrico; catastro inmobiliario.

\section{Abstract}

The Supreme Court accepted an appeal on the merits, considering that the piece of land which ownership was claimed was sufficiently specified with the sketch submitted by the plaintiff and prepared by a surveying engineer. That drawing was made according to the boundaries indicated in the registration on the Land Registry, and the topographical survey was corroborated by the personal inspection made by the court. The use of yards as a measure

\footnotetext{
* Profesor asociado de Derecho Privado, Pontificia Universidad Católica de Chile. Correo electrónico: jcalcald@uc.cl.
} 
to mark out the boundaries does not prevent the correct specification of the claimed land.

Keywords: action for the recovery of the ownership; demarcation, boundaries; metric system; land registry.

\section{LA CUESTIÓN DEBATIDA}

El 20 de abril de 2016, José Richard Chávez Cabezas presentó una demanda de reivindicación de retazo de inmueble urbano en contra de José Alejandro Amdan Ormeño ante el Juzgado de Letras y Garantía de Cabrero, por la cual solicitaba que este último fuese condenado a restituirle una franja de $80,88 \mathrm{~m}^{2}$ que le pertenecían y que ocupaba sin título alguno.

La demanda estaba fundada en que José Richard Chávez Cabezas era dueño del inmueble urbano consistente en sitio y casa ubicado en la calle Tucapel 202, comuna de Cabrero, cuyos deslindes son: al norte, con Arístides Ormeño; al sur, con Juan Sánchez; al oriente, con Luis Vial; al poniente, con calle Tucapel. El referido inmueble mide 12,5 varas de frente por la calle Tucapel y 50 varas de fondo, y se encontraba inscrito a nombre del demandante a fojas 2523, núm. 1282 del Registro de Propiedad del año 2013 a cargo del 252 Conservador de Bienes Raíces de Cabrero. La adquisición de dicho inmueble se había hecho de manera parcial, sumando diversas cesiones de derechos hasta fusionar en una sola inscripción las distintas cuotas hereditarias existentes.

El demandante explicaba que, al elaborar el proyecto de edificación de un lubricentro y practicar la mensura del predio y su conversión al sistema métrico decimal, se pudo determinar que el demandando tenía ocupada una superficie de $80,88 \mathrm{~m}^{2}$, la cual equivalía a un trapezoide de las siguientes medidas: al norte, $41,8 \mathrm{~m}$; al sur, $41,77 \mathrm{~m}$; al oriente, $3,38 \mathrm{~m}$; al poniente, $1,48 \mathrm{~m}^{1}$. Para mayor claridad, precisaba que se trataba de una franja que deslindaba al norte con su predio, que tenía $1,48 \mathrm{~m}$ de frente por calle Tucapel y se proyectaba hacia atrás con la misma extensión de fondo que el inmueble que le pertenece. Acompañó junto a la demanda un croquis elaborado por el ingeniero agrimensor Alexis Hernán Navarro Álvarez, donde el retazo reclamado corresponde a la zona achurada.

Agregaba la demanda que el demandado era poseedor inscrito de un inmueble urbano situado al norte del sitio y casa que conforman el predio de su propiedad. Según la inscripción que se lee a fojas 816, núm. 453 del Registro

\footnotetext{
${ }^{1}$ En todas las sentencias se habla de un "rectángulo irregular". Sin embargo, un rectángulo es un paralelogramo que tiene los cuatro ángulos rectos y los lados contiguos desiguales. En el caso analizado, el retazo reclamado no tiene todos sus lados igual, de suerte que comporta en realidad un trapezoide, vale decir, un paralelogramo que tiene los cuatro ángulos rectos y los lados contiguos desiguales.
} 
de Propiedad del año 2015 a cargo del Conservador de Bienes Raíces de Cabrero, el bien raíz del demandado tiene una superficie total de $466,01 \mathrm{~m}^{2}$, con un frente de 10,45 m por calle Tucapel. Dicho título proviene de la constitución de dominio efectuada a nombre de Irma Ormeño Bailey merced al procedimiento de saneamiento del DL 2695/1979, quien con posterioridad vendió el inmueble al demandado por escritura pública de 30 de marzo de 2012. Pese a este dominio sobre el predio vecino, el demandando violaba el derecho de propiedad que corresponde al demandante y también su posesión material y legal respecto del retazo singularizado, puesto que había realizado actos propios del dominio, como cerramiento y edificación, sin que hubiese título alguno que lo permitiera, de suerte que debía ser considerado como poseedor de mala fe.

Sobre la base de estos antecedentes, el actor pedía al tribunal que el demandado fuese condenado a restituirle la porción de terreno que ocupaba de manera ilegítima junto con las demás prestaciones accesorias que indicaba.

Debidamente emplazado, José Alejandro Amdan Ormeño compareció en el juicio oponiendo la excepción de prescripción adquisitiva y, en subsidio, contestó la demanda, solicitando al tribunal su rechazo, con costas.

Como cuestión previa, el demandado señaló que era dueño de la propiedad inscrita a fojas 816, núm. 453 del Registro de Propiedad del año 2015 a cargo del Conservador de Bienes Raíces de Cabrero. Dicho inmueble se encuentra situado en calle Tucapel 200, comuna de Cabrero, y sus deslindes son: al norte, con Asdrubal Rozas en línea quebrada de 9,80, 0,55 y 34,22 m; al sur, con sucesión Vásquez Sánchez en 44,74 m; al este, con Ilustre Municipalidad de Cabrero en 10,26 m; al oeste, con calle Tucapel en 10,45 m. Fue adquirido por compraventa a Irma Ormeño Bailey, cuya inscripción constaba a fojas 360, núm. 183 del Registro de Propiedad del año 2012 a cargo del Conservador de Bienes Raíces de Cabrero. Dicha inscripción justificaba la adquisición originaria que provino del Ministerio de Bienes Nacionales mediante el procedimiento de saneamiento del DL 2695/1979, que había concluido en 2011.

La excepción de prescripción adquisitiva opuesta se fundaba en el art.15 del DL 2695/1979. Dado que la antecesora del demandado había adquirido el bien raíz de manera constitutiva mediante la resolución de regularización de la Seremi de Bienes Nacionales, y ella se había inscrito en el Conservador de Bienes Raíces de Cabrero con fecha 23 de febrero de 2012, eso significaba que había operado a su respecto la prescripción adquisitiva del mentado art. 15 del DL 2695/1979 al haber transcurrido más de un año completo desde dicha inscripción ${ }^{2}$. De igual modo, la acción del demandante había prescrito de forma refleja, por desaparecer a su respecto el derecho que la amparaba.

Respecto de la pretensión del actor, el demandado argumentó que ella debía ser rechazada porque los títulos no individualizaban de forma adecua-

\footnotetext{
${ }^{2}$ En 2018, la Ley n. ${ }^{\circ} 21108$ modificó el art. 15 del DL 2695/1979, ampliando el plazo de prescripción adquisitiva de uno a dos años. GOLDENBERG (2019) analiza algunas de las modificaciones introducidas por esa ley.
} 
da el predio de mayor superficie que le correspondía y al cual le faltaría un retazo, siendo una cuestión difícil de resolver la determinación de qué era aquello sobre lo cual aquel tenía derecho y que pedía al tribunal que se le restituyese. La razón estribaba en que su inscripción conservatoria solo describía un inmueble que tiene 12,5 varas de frente por 50 varas de fondo situado en la calle Tucapel 202, comuna de Cabrero, sin que en ella se precisase la superficie total, la longitud de los linderos o los predios con los cuales aquel deslinda. Para suplir esa falta de información, el demandante acompañó un plano inexacto que no había sido confeccionado a partir de las inscripciones de dominio de las dos partes en disputa, ni cumplía con las características técnicas de un levantamiento topográfico. Esta falta de claridad respecto del bien raíz de su propiedad incidía sobre la identidad material de aquella franja que se reclamaba en el judicio.

El conflicto se producía porque el demandante acusaba que en el lindero este del inmueble del demandado existiría una superficie añadida que le pertenecía. La controversia nacía de que dicho bien no se encontraba debidamente individualizado a partir del título inscrito del demandante, siendo necesario suplirlo mediante planos e informes. Dado que la reivindicación persigue la restitución de una cosa singular de la que no se está en posesión, correspondía rechazar la acción intentada por la falta de un requisito indispensable y relativo a la individualización perfecta del bien reclamado. Esta exacta individualiza254 ción es lo que permite distinguir un juicio reivindicatorio de una acción de demarcación y cerramiento.

De cualquier manera, incluso, si no hubiese duda de cuál era el bien que se quería reivindicar, el actor tampoco era dueño del retazo que señalaba en su demanda, por haber adquirido por prescripción la antecesora de demandante el predio que ocupa en la actualidad y al que pertenece el área discutida. Esto trajo consigo que las anteriores inscripciones conservatorias fueron canceladas por el solo ministerio de la ley, quedando privado el demandante de la fracción de terreno que pretendía reivindicar, si es que alguna vez le correspondió algún derecho sobre ella. Por lo demás, el demandando añadía que la delimitación de su predio se desprendía de la sola inscripción conservatoria que existía a su nombre, donde se individualiza el inmueble con sus respectivos deslindes y una longitud para cada uno de ellos, reflejando así la información contenida en el plano levantado por la Seremi de Bienes Nacionales del Biobío y archivado en el Conservador de Bienes Raíces de Cabrero.

A partir de esos antecedentes, el demandado solicitó que se tuviese por opuesta la excepción de prescripción adquisitiva, se la acogiera a tramitación y se declarase que la acción reivindicatoria ejercida se encontraba prescrita, con costas. En subsidio, pidió tener por contestada la demanda y que ella fuese rechazada en todas sus partes, también con costas.

El tribunal dio a la prescripción la tramitación de una excepción dilatoria, confiriendo traslado al actor. En su escrito, este arguyó que no procedía que dicha excepción fuese tratada como una cuestión previa, porque tenía un ca- 
rácter perentorio y correspondía resolverla junto con la cuestión de fondo que era materia del juicio por incidir sobre la existencia del derecho de dominio que alegaba como fundamento de su demanda. Además, y aun cuando era cierto que el demandado era sucesor en el dominio del predio de Irma Ormeño Bailey, quien lo había regularizado de acuerdo con el procedimiento del DL 2695/1979, la prescripción que había operado a su favor se refería solo al inmueble que había sido objeto del respectivo procedimiento de saneamiento, sin afectar una extensión de terreno que era ajena a los deslindes de aquel. La razón era que la franja que se reivindicaba se encontraba al sur del bien raíz del demandado y al norte del predio del demandante, sin formar parte del primero.

Proveyendo la cuestión previa, el tribunal decidió que la excepción de prescripción opuesta por el demandado se resolviera junto con el asunto principal, y tuvo por contestada la demanda, confiriendo traslado para replicar.

En su réplica, el actor reiteró los argumentos expuestos en su demanda. Insistió que el inmueble del demandado era un bien distinto, que deslinda en $10,45 \mathrm{~m}$ con la calle Tucapel, y que el retazo que revindicaba se encontraba perfectamente delimitado en sus linderos y superficie. De esta forma, al demandado le correspondía una superficie de $466,04 \mathrm{~m}^{2}$, que era la cabida de la constitución de dominio operada a favor de Irma Ormeño Bailey de parte del Seremi de Bienes Nacionales del Biobío, mientras que la ocupación material efectiva alcanzaba los 587,52 $\mathrm{m}^{2}$. De ellos, $80,88 \mathrm{~m}^{2}$ correspondían al demandante según se desprende de su respectiva inscripción conservatoria.

La dúplica fue evacuada en rebeldía del demandado, quien tampoco compareció a la conciliación ni aportó prueba de ninguna especie durante el juicio.

Por sentencia de 23 de marzo de 2018, el Juzgado de Letras y de Garantía de Cabrero acogió la demanda reivindicatoria y ordenó que el demandado restituyera el inmueble objeto del litigio, libre de todo morador, en el plazo de treinta días desde que la sentencia cause ejecutoria, bajo el apercibimiento de ser lanzado por la fuerza pública. El fallo rechazó la excepción de prescripción adquisitiva opuesta por el demandado y lo condenó en costas, al haber sido vencido totalmente. La premisa que fundaba esta decisión era que el demandante debía acreditar las circunstancias que justifican la pretensión ejercida, y que consisten en que se trate de una cosa susceptible de ser reivindicada, que ella sea singular e individualizada, que el reivindicador sea el dueño de la cosa y esté privado de su posesión, que la acción se dirija contra el actual poseedor, y que ella no se encuentre prescrita (cons. $11^{\circ}$ ).

De los documentos acompañados, el tribunal dio por establecido que "el actor justificó ser poseedor inscrito del inmueble ubicado en calle Tucapel núm. 202 de la ciudad y comuna de Cabrero" (cons. 12 $2^{\circ}$. La prueba testimonial sirvió para tener por acreditado "que la superficie que reivindica el actor, el demandado la mantiene en su poder[,] haciendo uso de ella y realiza actos propio de dueño" (cons. $13^{\circ}$ ). Para determinar la superficie del área en disputa, la sentencia consideró relevantes 
"el plano confeccionado por el Ministerio de Bienes Nacionales que sirvió de base y que forma parte de la resolución de la SEREMI de Bienes Nacionales que ordenó la inscripción del predio de la demandada, donde consta que el frente [...] a la calle Tucapel es de 10,45 metros y no de 13 metros" (cons. $14^{\circ}$ ),

y la inspección personal del tribunal, donde este "pudo percibir directamente la zona en conflicto, incluyendo un croquis en el acta, y procediendo a medir la zona" (cons. $15^{\circ}$ ). A juicio del tribunal, por tanto, los antecedentes aportados permitían determinar que concurrían en la especie "los presupuestos fácticos y jurídicos de la acción reivindicatoria" (cons. $15^{\circ}$ ) y correspondía acoger la demanda, ordenando al demandado restituir el retazo que ocupaba dentro de treinta días a que la sentencia causase ejecutoria (cons. $16^{\circ}$ ).

La sentencia definitiva fue complementada dos veces. Por resolución de 11 de julio de 2018, se precisó que se condenaba al demandado, en su calidad de poseedor de mala fe, a restituir el inmueble situado en calle Tucapel 202, comuna de Cabrero, que se individualiza como un retazo de $1,48 \mathrm{~m}$ de frente por dicha calle Tucapel por $41,8 \mathrm{~m}$ de fondo por el lado norte y $2,38 \mathrm{~m}$ por el lado oriente, libre de todo gravamen, en el plano señalado en la sentencia de 23 de marzo de 2018. Por resolución de 11 de octubre de 2018, se complementó por segunda vez dicha sentencia, agregando que el retazo a restituir tenía una 256 extensión de $41,77 \mathrm{~m}$ por el lado sur.

La sentencia de primera instancia fue apelada por el demandado. Su recurso se basada en que la prueba aportada solo era suficiente para concluir que el actor era dueño de un inmueble urbano situado en la calle Tucapel 202, comuna de Cabrero, con una extensión de 12,5 varas por dicha calle y 50 varas de fondo. Por el contrario, aquel no logró acreditar que tenía propiedad sobre el retazo situado en el inmueble urbano identificado con el núm. 200-B de la mentada calle Tucapel, puesto que el plano acompañado junto con la demanda no hacía referencia a que esa franja fuese independiente del predio del demandante y de aquel que pertenece al demandado. Agregaba el recurso que el actor nunca señaló los metros y deslindes de dicha extensión de terreno que reclamaba, limitándose a acompañar un plano elaborado por un ingeniero agrimensor, donde se da cuenta de una superficie ocupada ascendente a 80,88 $\mathrm{m}^{2}$. De esto sigue que en la demanda faltaba la determinación del objeto que se pretendía reivindicar, siendo este un presupuesto de dicha acción. Tampoco se rindió prueba idónea para determinar la cabida y deslindes del retazo reclamado, ni se efectuó la conversión de varas a metros, dado que la inscripción conservatoria del demandante se encontraba expresada en la primera de esas unidades de medida. Por eso, el demandado solicitó al tribunal de alzada que acogiera la apelación y revocase el fallo de primer grado, rechazando la demanda, con costas.

Por sentencia de 1 de febrero de 2019, la Corte de Apelaciones de Concepción acogió la apelación del demandado y revocó el fallo de primer grado, 
aunque sin condena en costas del juicio ni de la instancia. El fundamento de esta decisión provino de que "la forma y medidas exactas del retazo que se pretende reivindicar no se encuentran suficientemente determinadas" (cons. $10^{\circ}$ ), de suerte que,

"al no concurrir un elemento fundamental de procedencia de la pretensión ejercida por el actor, correspondía rechazar la demanda de autos" (cons. $11^{\circ}$ ).

A juicio de la Corte, la situación discutida

"hacía necesaria una prueba de mayor rigor técnico, donde un perito, teniendo en cuenta todos los antecedentes puestos a disposición, pudiera determinar la forma y la ubicación exacta del retazo ocupado" (cons. $10^{\circ}$ ).

De hecho, una muestra de la deficiencia en la individualización de la franja controvertida era "la manera como se especificó sucesivamente el inmueble a reivindicar en el fallo de primer grado, incluidas sus complementaciones" $\left(\right.$ cons. $\left.10^{\circ}\right)$. La inspección personal del tribunal no era suficiente para satisfacer la fijación exacta de los deslindes de ambos predios, puesto que en ella el juez

"se limitó a anotar las medidas tomadas por la parte demandante de los deslindes del costado poniente de cada inmueble, sin realizar igual medición del resto de los deslindes de éstos, así como también la distancia de cada inmueble respecto de las calles que podían servir de referentes estables" (cons. $10^{\circ}$ ).

El demandante interpuso recursos de casación en la forma y en el fondo en contra del fallo de segunda instancia. Por el primero de ellos denunciaba que la Corte de Apelaciones de Concepción había incurrido en el vicio de ultra petita del art. 768 , núm. $4^{\circ}$ del $C P C$, puesto que rechazó la demanda por argumentos no invocados por la parte apelante, vulnerando el principio de congruencia procesal. El recurso de casación en el fondo estaba fundado en la infracción del art. 889 del $C C$ en relación con el art. 409 del $C P C$, y también de los arts. 408 y 428 del CPC. Las dos primeras normas se infringían porque el fallo de segunda instancia se había basado en la inexistencia de un informe de peritos, pese a que este medio de prueba no tiene el carácter de diligencia obligatoria en un juicio reivindicatorio. De esa forma, el actor quedaba en la indefensión, dado que un inmueble que se encontraba perfectamente individualizado no se restituía por la exigencia de una actuación procesal que la ley no exige de manera imperativa. El art. $408 \mathrm{del} C P C$ se consideraba infringido, porque el tribunal de alzada había restado valor a la inspección personal del tribunal, pese a que esta hace plena prueba respecto de los hechos materiales que el juez observa durante su realización. En fin, el art. 428 del $C P C$ se 
denunciaba infringido, por cuanto la Corte de Apelaciones de Concepción estimó que la prueba documental (el croquis acompañado con la demanda) y la inspección del tribunal (el dibujo hecho en el acta levantada al efectuar las mediciones en terreno) eran contradictorias, pero sin elegir una sobre la otra, como se ordena en dicha regla. A juicio del recurrente, todas estas infracciones influían de forma sustancial en lo dispositivo del fallo de segunda instancia y ameritaban su invalidación y la dictación de una sentencia de reemplazo que acogiera la demanda, confirmando así lo resuelto por el Juzgado de Letras y de Garantía de Cabrero.

Por sentencia de 13 de agosto de 2020, la Corte Suprema rechazó el recurso de casación en la forma y acogió el de casación en el fondo, dejando sin efecto el fallo de segunda instancia y dictando la correspondiente sentencia de reemplazo.

El recurso de casación en la forma fue rechazado por una razón de índole procesal. La Corte Suprema recordó que dicho vicio "ataca la falta de adecuación de entre las pretensiones formuladas por las partes" (cons. $3^{\circ}$ ). Sin embargo, en el caso en cuestión, el tribunal de alzada se limitó a resolver lo pedido, rechazando la demanda en su integridad por los fundamentos que expone de manera lata $\left(\right.$ cons. $3^{\circ}$ ). La Corte de Apelaciones de Concepción conoció de un recurso de apelación y enmendó con arreglo a derecho lo resuelto en primera instancia, de suerte que el principio de congruencia no se vio afectado.

258 Este exige que "los jueces se aboquen a resolver todo lo pedido; ni más ni menos" (cons. $3^{\circ}$ ). Así ocurrió en autos y, por tanto, el recurso de casación en la forma debía ser rechazado, por no estar configurado el vicio denunciado (cons. $4^{\circ}$ ).

Respecto del recurso de casación en el fondo, este fue acogido (cons. $16^{\circ}$ ). $\mathrm{El}$ argumento decisorio fue que el primer vicio denunciado

"se produce cuando la Corte niega la individualización del bien, exigiendo una prueba que no ha sido rendida en la instancia, como si la efectivamente anexada e insistimos no debatida por el demandado, no fuera suficiente" (cons. $\left.13^{\circ}\right)$.

De esto se sigue que "la sentencia cuestionada efectivamente olvida los antecedentes aportados por el actor[,] quien [...] debía acreditar sus dichos" (cons. $14^{\circ}$ ). Para concluir como lo hizo,

"la Corte recurrida soslaya la prueba consiste en la inspección personal del tribunal, [...] donde se ratifica que el retazo de terreno cuya reivindicación se pide está en el límite de los terrenos de ambos partes, colindantes por el lado norte del terreno del actor, y corre hasta el fondo en un rectángulo irregular [sic], cuyas medidas constan en autos y lo hacen perfectamente identificable" (cons. $15^{\circ}$ ). 
A mayor abundamiento, el croquis acompañado por el demandante junto con la demanda y el dibujo hecho durante la inspección personal del tribunal muestran dos trapezoides que "están ubicados en el mismo espacio de tierra, siendo, entonces, clara la ubicación y extensión del retazo" (cons. 15º. Esto significa que el bien raíz reclamado se encontraba correctamente singularizado y se podía distinguir del predio del demandado, de suerte que era susceptible de ser reivindicado. Por el contrario, la Corte Suprema consideró que la infracción de los arts. 408 y 428 del $C P C$ no podía ser materia de control de casación, porque esas normas se referían a la apreciación de la información probatoria aportada y que corresponde de manera exclusiva a los jueces del fondo, sin integrar el bloque conocido como "reglas reguladoras de la prueba" (cons. $14^{\circ}$ ).

Acto seguido, la Corte Suprema dictó la sentencia de reemplazo que confirmó la sentencia de primer grado, sin condena a las costas del recurso. El fundamento argüido fue que

"las conclusiones alcanzadas en la instancia se construyen conforme al mérito de autos y sin que se encuentren contradichas por antecedente alguno, existiendo suficiente material probatorio que constituye plena prueba sobre la propiedad del actor en el terreno, la ocupación irregular que de éste hace el demandado y los detalles del bien" (cons. $4^{\circ}$ ).

Correspondía, entonces, acoger la demanda y dar lugar a la reivindicación del retazo (cons. $\left.5^{\circ}\right)$.

\section{COMEnTARio}

El caso relatado presenta varias cuestiones de interés, aunque no todas ellas tienen la misma relevancia. Los dos aspectos más interesantes son la subyacente delimitación entre la acción reivindicatoria y la acción de demarcación (1), y la individualización de la finca registral de acuerdo con el derecho chileno (2), que tiene una coda en las innovaciones que incorpora el proyecto de reforma del sistema notarial y registral en sus aspectos orgánicos y funcionales, que se discute en el Congreso (3). Queda fuera el análisis si la excepción de prescripción es una excepción dilatoria o perentoria según la terminología del $C P C^{3}$, el sentido de la prueba pericial dentro de un juicio reivindicatorio, la forma de valoración de la prueba aportada dentro del proceso civil $^{4}$, y también el alcance de la pres-

\footnotetext{
${ }^{3} \mathrm{El}$ art. 304 del $C P C$ solo admite que se tramiten como dilatorias las excepciones de cosa juzgada y prescripción. Distinto es el caso en material laboral, donde la excepción de prescripción se debe resolver de manera preliminar, siempre que su fallo se pueda fundar en antecedentes que consten en el proceso o que sean de pública notoriedad (art. 453, núm. 1 del Código del Trabajo). Lo mismo se prevé para el juicio ante los juzgados de familia (art. 61, núm. 2 de la Ley n. ${ }^{\circ}$ 19968).

${ }^{4}$ La valoración de la prueba avanza hacia el sistema de la sana crítica. Por ejemplo, el proyecto de ley que reforma el sistema de justicia para enfrentar la situación posterior a la pandemia
} 
cripción adquisitiva del art. 15 DL 2695/1979, sobre la cual se ha tratado en un comentario anterior ${ }^{5}$.

Con carácter previo, conviene hacer una precisión para distinguir dos conceptos que a veces se confunden. Se trata de la constitución como modo de adquirir el dominio y del carácter constitutivo de la inscripción conservatoria.

En rigor, los modos de adquirir el dominio se encuentran enumerados en el art. 588 del $C C^{6}$, y ahí no se incluye uno llamado "constitución”. Sin embargo, existen otros modos que tampoco están mencionados en esa norma, como sucede con la ley, la expropiación, el comiso, la requisición y la confiscación"7. $\mathrm{El}$ art. 52, núm. $1^{\circ}$ del RRCBR sí menciona de forma refleja la constitución de un derecho real cuando refiere las inscripciones que se debe practicar en el Registro Inmobiliario ${ }^{8}$. Este modo alude al surgimiento de un derecho real por primera vez, como paso previo a que circule en el tráfico ${ }^{9}$.

Por su parte, el carácter constitutivo de la inscripción conservatoria alude a que la mutación de la titularidad se produce con la respectiva entrada en el Registro. Su opuesto es el carácter declarativo, donde solo se deja constancia a través de la inscripción de una mutación producida fuera del Registro. Por cierto, esto no significa que la inscripción no pueda ser contradicha ${ }^{10}$. La función de la inscripción conservatoria es principalmente de legitimación, de suerte que su finalidad se endereza a asegurar la conservación de la autoridad del respectivo ordenamiento en la fijación de las titularidades ${ }^{11}$. Jerónimo González (1875-1946) ha expresado esta idea de manera concisa, pero certera:

"La técnica moderna concede a la inscripción, respecto de los inmuebles, las mismas funciones legitimadoras que a la posesión corresponden en el orden de los muebles"12.

Esto significa que la posesión y la inscripción son mecanismos técnicos para expresar un concepto normativo relativo al aprovechamiento económico de las cosas, que en sí es una cuestión cuya demostración se debe obtener a partir de las circunstancias concretas del caso ${ }^{13}$. De ahí que al titular le baste con aportar la inscripción que existe a su favor para ser tenido por tal y para justificar ante

de Covid-19 (Boletín núm. 13.752-07) reemplaza el art. 384 del $C P C$ y ordena que la prueba de testigos, ya sin tacha previa, sea ponderada de esa manera.

${ }^{5}$ Alcalde (2016), pp. 254-263.

${ }^{6}$ La materia es objeto de reserva legal: "Sólo la ley puede establecer el modo de adquirir la propiedad, de usar, gozar y disponer de ella y de las limitaciones y obligaciones que deriven de su función social” (art. 19, núm. 24 II de la $C P R$ ).

${ }^{7}$ Corral (2020), pp. 357-361.

${ }^{8}$ Zárate (2019), pp. 414-416.

${ }^{9}$ GuZMán (1995), pp. 175-176.

${ }^{10}$ Alcalde (2019b), pp. 48-51.

${ }^{11}$ Von Bar (2019), p. 713.

${ }^{12}$ González y Martínez (2009), pp. 121-122.

${ }^{13}$ VON BAR (2019), p. 715. 
terceros que lo es $^{14}$, porque es ella la que da cuenta, según la decisión adoptada por el sistema jurídico, de aquella investidura real o aparente de un derecho ${ }^{15}$ que distingue la tenencia posesoria de la mera tenencia (art. $715 \mathrm{del} C C$ ).

Cuestión diversa es que la inscripción sea inatacable, puesto que ese efecto solo se produce cuando un determinado ordenamiento ha optado por un sistema abstracto. Si esto sucede, el convenio traslativo seguido de una inscripción produce la mutación del derecho, haciendo que las vicisitudes del título no afecten la transferencia; salvo contadas excepciones, ella siempre se mantiene como mecanismo de resguardo hacia el adquirente y terceros. Como se ha explicado en otro lugar, en Chile la inscripción conservatoria es prueba de dominio (art. 686 del $C$ C) y también de posesión (arts. 696, 724, 728 y 925 del $C C$ ), lo que no significa que esa prueba sea irrefutable o que el verdadero dueño quede desprotegido; se trata de una prueba simplemente legal, que invierte la carga probatoria respecto de quien desea controvertir la titularidad que surge de la inscripción conservatoria ${ }^{16}$. El juicio reivindicatorio está basado, entonces, en un juego de presunciones ${ }^{17}$.

Distinto de estos dos conceptos es la clasificación que distingue entre modos de adquirir originarios y derivativos: los primeros son aquellos donde el derecho se adquiere con independencia de la titularidad de un antecesor, mientras que en los segundos el derecho se traspasa a otro titular con sus mismas calidades, vicios y gravámenes ${ }^{18}$. Aquí la cuestión relevante es la comunicación que se produce entre transferente y adquirente en un caso (art. 682 del $C C$ ), y que está ausente en el otro (por ejemplo, art. 16 del DL 2695/1979).

\section{La acción reivindicatoria y la acción de demarcación}

La delimitación entre la acción reivindicatoria y la acción de demarcación ha sido objeto de atención por parte de la doctrina y la jurisprudencia ${ }^{19}$. Para lo que aquí interesa, y dado que el punto solo fue levantado por el demandando al contestar la demanda, sin que haya incidido en el razonamiento judicial posterior, basta con algunas consideraciones generales al respecto. Ambas acciones presentan diferencias en cuanto a sus objetos, legitimados, prueba y carga probatoria, y procedimiento aplicable ${ }^{20}$. La demarcación tiene por objetivo que se fijen los límites que separan el predio del demandante de los predios colindantes (art. 842 del $C C$ ). Ella busca, entonces, que se individualice cuál es el inmueble sobre el que el actor tiene propiedad, fijando sus linderos.

\footnotetext{
${ }^{14}$ Rams, Moreno, Rubio (2020), p. 62.

${ }^{15}$ Mensaje del Código Civil, § 24.

${ }^{16}$ Alcalde (2019b), p. 60.

${ }^{17}$ KiPER (2010), p. 231.

${ }^{18}$ Peñallillo (2019), p. 599.

${ }^{19}$ Véase, por ejemplo, Melo (2006), Lathrop (2011), Rabat, Mauriziano (2011) y Fuentes (2020), además de las referencias en los manuales y tratados al uso.

${ }^{20}$ Fuentes (2020), pp. 107-110.
} 
La acción reivindicatoria persigue la restitución de aquella cosa que pertenece al demandante y cuya posesión no tiene, por estar en ella el demandando (arts. 889,893 y 895 del $C C$ ). Para que proceda la reivindicación basta que se trate de una inmueble (art. 890 del $C C$ ) y que este tenga el carácter de una cosa singular (art. 889 del $C$ C), lo que significa que el bien reclamado constituya una unidad, sea natural o artificial, y que se determinen los contornos que ella tienen ${ }^{21}$. El actor debe indicar con claridad cuál es la situación, cabida y linderos del predio cuya restitución pide al tribunal ${ }^{22}$.

Esto significa que la discusión del juicio comentado fue correcta: el actor ejerció una acción reivindicatoria destinada a que le restituyeran un retazo de terreno que, perteneciendo al inmueble de su propiedad, estaba anexada en la práctica al predio del demandado, quien lo ocupaba entonces materialmente, incluso habiendo hecho un cerramiento. En este sentido, tanto los jueces de instancia como la Corte Suprema resolvieron de manera correcta el asunto, pues no prestaron atención a la reclamación del demandado de tratarse de una acción de demarcación. El objeto pedido por el actor era el propio de un juicio reivindicatorio, y sobre esto versó la discusión y la prueba. Sin embargo, esta claridad sobre la naturaleza de la pretensión ejercida no significa que no existiese otro problema conexo.

Uno de los puntos discutidos en torno a la singularización del inmueble se produce cuando se trata de casos de reivindicación parcial, donde se reclama 262 una parte o sector de un predio (y no de una cuota o parte ideal) que el demandante señala ser suyo y se encuentra en poder de un vecino o de un tercero ${ }^{23}$. Esto aboca a una cuestión de la que se ha ocupado el derecho registral, como son los distintos significados que tiene una finca para el derecho. De ello se trata en el apartado siguiente.

\section{La configuración de la finca registral}

$\mathrm{El}$ art. 568 del $C C$ señala que los bienes raíces, llamados también inmuebles o fincas, son aquellas cosas que no se pueden transportar de un lugar a otro, como sucede con las tierras y minas ${ }^{24}$. Dentro de esta clase de bienes hay una especie constituida por las casas y heredades, que reciben el nombre de predios o fundos (art. 568 II del CC). La diferencia que presenten los bienes raíces con las cosas muebles (art. $567 \mathrm{del} C C$ ) es que primero se debe producir

${ }^{21}$ PeÑailillo (2019), pp. 216 y 1397.

${ }^{22}$ Mejías (2018), p. 44.

${ }^{23}$ PeÑallillo (2019), p. 1399.

${ }^{24} \mathrm{El}$ art. 28 del Código de Minería señala que la concesión minera, sea de exploración o de explotación (art. $\left.2^{\circ} \mathrm{II}\right)$, “configura un sólido cuya cara superior es, en el plano horizontal, un paralelogramo de ángulos rectos, y cuya profundidad es indefinida dentro de los planos verticales que lo limitan". La medida de los lados de la concesión tiene ciertos mínimos, y la ley señala la superficie máxima que ella puede comprender. 
el objeto cuyas relaciones jurídicas se regulan enseguida ${ }^{25}$. La razón es que la tierra está por naturaleza indivisa, de suerte que su parcelación es siempre algo convencional y se endereza a asegurar tanto el ejercicio de la soberanía del respectivo país como un mejor aprovechamiento de esa tierra para fines de vivienda y explotación ${ }^{26}$.

Respecto de los predios, se suele distinguir tres conceptos de finca: material, registral y catastral. La finca material es el "trozo de la superficie terrestre cerrado por una línea poligonal y objeto de propiedad" 27 . Por su parte, la cualidad de finca registral "la determina una circunstancia puramente formal, como es la de figurar una cosa o un derecho inmueble como objeto de un folio registral" 28 . Esto significa que es tal todo lo que sirve para dar origen a una inscripción conservatoria. Una de las características del Registro Inmobiliario chileno es que no se exige plano, salvo ciertos casos señalados en leyes especiales (por ejemplo, en sede de copropiedad inmobiliaria y de saneamiento de la pequeña propiedad raíz), con lo que se dificulta el exacto emplazamiento territorial de un inmueble ${ }^{29}$. Tal era el caso discutido en el juicio que aquí se ha relatado.

Para identificar la finca en el Registro, el art. 78 del RRCBR señala que es necesario indicar "el nombre y los linderos del fundo" (núm. 4) ${ }^{30}$. Esta forma de individualización rige para los predios rústicos, puesto que en las zonas urbanas los inmuebles se inscriben en el Registro con referencia al número y calle en que se encuentran, sin mención de su nombre ${ }^{31}$. Con todo, hay que recordar que la venta de un predio rústico se puede hacer con relación a su cabida o como especie o cuerpo cierto (art. 1831 del $C C$ ). Una y otra forma de determinación del objeto vendido importa para las diferencias que pueda presentar la cabida real y la cabida declarada, vale decir, por la divergencia que se puede dar entre la extensión superficial que en realidad presenta el predio y aquella señalada en el contrato (art. 1832 del CC). En cambio, tratándose de un predio vendido como especie o cuerpo cierto, la cabida resulta indiferente, salvo que se haya vendido con señalamiento de linderos (art. 1833 del $C C$ ). De esto se sigue que, mientras la cabida no es un requisito indispensable para transferir un inmueble, sí lo es el señalamiento de sus deslindes, aunque sea por una exigencia registral. En otras palabras, la cabida no comporta una

${ }^{25}$ Rams, Moreno, Rubio (2020), p. 77.

${ }^{26}$ De ahí que Nino (2014), p. 210, señale: "forma parte esencial del concepto de propiedad una cierta relación normativa entre el individuo y los restantes".

${ }^{27}$ La definición se encuentra en la sentencia del Tribunal Supremo español de 10 de diciembre de 1960. En sentido similar, Peñallillo (2019), p. 191, señala: "Ser dueño de un inmueble por naturaleza es ser dueño de una sección del planeta que llamados Tierra”.

${ }^{28}$ Rams, Moreno, Rubio (2020), p. 79.

${ }^{29}$ Peñailillo (2019), p. 1400.

${ }^{30}$ Para la inscripción de la hipoteca, el art. 81, núm. 4 del RRCBR indica que se debe precisar "la situación de la finca y sus linderos". ZÁrATE (2019), pp. 444-445 y 448-451, refiere las fuentes de ambas normas.

${ }^{31}$ Vodanovic (2011), p. 260. 
circunstancia esencial para la identificación del predio revindicado si están claros sus deslindes ${ }^{32}$.

Por último, hay un concepto que en Chile existe, pero solo de manera parcial (principalmente con finalidades tributarias) ${ }^{33}$. Se trata del concepto de finca catastral, que expresa la representación gráfica de la riqueza territorial desplegada en el espacio. Para efectuar esta descripción es necesario considerar qué es lo que de verdad existe en un predio, con sus características concretas. De esta manera, la finca física delimita una determinada superficie de tierra, usando para ello un parámetro de medida de común aceptación; el Registro inmobiliario precisa ese bien en cuanto objeto de una determinada titularidad real, y la finca catastral efectúa una descripción pormenorizada sobre aquello que, en su dimensión tangible, existe dentro del predio. A diferencia de la finca física y la registral, la finca catastral necesita de un levantamiento cartográfico mayor, donde se refleje la zona o comarca de que se trata y la encadenación de predios que en ella existe ${ }^{34}$. Esa información se debe actualizar de manera periódica.

El caso que aquí se ha comentado versó sobre un problema relacionado con la conveniente delimitación de los deslindes de los predios de propiedad del demandante y del demandado, en especial de la zona de conflicto nacida en aquel lindero que unía a uno y otro. En rigor, la exigencia registral se satisface con indicar cuáles son los términos o líneas que separa un inmueble de otros, en cada uno de sus lados. No es necesario que esos linderos se precisen de acuerdo con una unidad de medida, sino que se utilice algún punto de referencia que permita distinguir hasta dónde se extiende el predio por cada punto cardinal. Por ejemplo, el DS de 14 de agosto de 1867, por el que se erigió el distrito $2^{\circ}$ Marchant, que formaba parte del Departamento de San Fernando, provincia de Colchagua (hoy, provincia de Cardenal Caro, Región de O'Higgins), señalaba para dicho distrito los siguientes deslindes:
"al Sur, el límite norte del distrito de Reto; al Este, los cerros de Pihuchén y Patagua hasta enfrentar las casas de don Agustín Silva y la Quebrada de los Caballos; al Norte, por una línea recta desde esta quebrada hasta la Poza Larga, y desde aquí hasta el deslinde poniente del Carrizal; al Oeste, este mismo deslinde hasta la loma de Galaz".

Cada uno de los lados del distrito estaba, entonces, delimitado por su referencia a un determinado accidente geográfico, sin indicar una medida concreta para cada uno de sus lados. Pero no había duda, al menos de manera referencial, sobre cuál era la extensión de dicho distrito.

Ante la falta de coincidencia sobre la individualización del inmueble reclamado, el principio debe ser que prevalecen los títulos por sobre la realidad

\footnotetext{
${ }^{32}$ González (2002), p. 36

${ }^{33}$ Alcalde (2019c).

${ }^{34}$ Peñallillo (2019), p. 790.
} 
física donde se haya emplazado el predio, porque esa es la consecuencia que impone aceptar la configuración registral del sistema de propiedad inmobiliario $^{35}$. En palabras de la Corte Suprema, "la singularidad del predio está siempre dada por el señalamiento de todos sus deslindes y en la forma señalada en la correspondiente inscripción" 36 . Por cierto, esto obliga a desplegar una labor de interpretación o adaptación de la redacción usada en dichos títulos, y también hace aconsejable que cada una de las partes, como parte de su respectiva pretensión o defensa, acompañe un plano o croquis que grafique con claridad cuál es la superficie sobre la que señala tener derecho, la cual podrá ser confrontaba con una identificación topográfica, si así resulta indispensable $^{37}$. Así ocurrió en el presente caso, tanto con el croquis que el demandante aportó con su demanda como con aquel dibujo que el tribunal recogió en el acta de la inspección personal realizada al predio, después de haber medido cada uno de sus linderos.

Un punto que puede dar lugar a discusión es el patrón de medida utilizado para señalar los linderos. En el RRCBR no hay obligación de usar el sistema métrico decimal, pese a que fue establecido en el país por la Ley de 29 de enero de 1848 sobre pesos y medidas. La razón es que las inscripciones repiten los deslindes de aquellas que las preceden, de manera que se ha perpetuado aquel sistema de medición que el art. 14 de la citada ley permitía respecto de "todos los contratos i escrituras de compras i ventas anteriores a la introducción del sistema métrico decimal". Ahí residía la dificultad respecto del predio del demandado, donde sus deslindes estaban indicados en varas, a diferencia del inmueble del demandado que, por provenir de una constitución producida merced a la inscripción de la resolución de regularización del DL 2695/1979, tenía sus deslindes expresados en metros y contaba con un plano levantado como parte de dicho procedimiento (art. 10 III del DL 2695/1979), el cual fue archivado en el Conservador al momento de practicar dicha inscripción (art. 14 del DL 2695/1979). Sin embargo, esto no significa un problema práctico, como pretendía el demandado, porque el referido art. 14 de la Ley de Pesos y Medidas señala que una vara equivale a $0,836 \mathrm{~m}^{38}$. De esta manera, bastaba una simple operación aritmética para saber cuántos metros tenía cada uno de los linderos del predio del demandante, como lo hizo el Juzgado de Letras y de Garantía de Cabrero y la Corte Suprema. De igual manera, la cabida del

${ }^{35}$ SePúlveda (2014), pp. 132 y 144.

${ }^{36}$ SCS, 23 de julio de 2014, rol núm. 1755-2013; CL/JUR/4042/2014, cons. $5^{\circ}$.

${ }^{37}$ Peñailillo (2019), p. 1400.

${ }^{38}$ La vara fue una unidad de longitud utilizada en España, Portugal, Iberoamérica y otras regiones con influencia de dichas metrópolis. Equivalía a tres pies. Sin embargo, cada región tenía distintos valores para ella según sus necesidad o usos. De ahí que su longitud oscilaba entre $0,8359 \mathrm{~m}$ la vara de Alicante y $0,768 \mathrm{~m}$ la de Teruel. La más empleada era la vara castellana o vara de Burgos, cuya equivalencia era de 0,835905 m. Como se observa, es esta última la que, aproximada, se usa en la Ley de Pesos y Medidas de 1848. De RAMón y LaRRAín (1979), p. 30, explican que una cuadra, según el padrón de Santiago, debía medir dieciocho varas. 
predio se podía determinar sin problemas multiplicando el ancho y el largo, una vez hecha la conversión métrica anterior.

Pues bien, estas consideraciones permiten sostener que la decisión de la Corte Suprema fue correcta. La singularización del bien reclamado se debe hacer conforme a los parámetros que da el derecho vigente, y así ocurrió. La prueba pericial solo es obligatoria en aquellos casos en que la ley ordena que ella sea tenida en cuenta (arts. 409 y $410 \mathrm{del} C P C$ ), siendo facultativo en los casos en que exista algún punto de hecho para cuya apreciación se necesite conocimientos especiales de alguna ciencia o arte (art. 411, núm. $1^{\circ}$ del $C P C$ ). El caso comentado no pertenecía a esta clase, porque bastaba con interpretar las inscripciones conservatorias a la luz de los elementos fácticos que determinaban el efectivo emplazamiento de los predios del demandante y del demandado o, si se prefiere, era suficiente con confrontar la finca registral con la finca física, lo cual se hizo en terreno. Para ello, no había más que realizar una inspección personal del tribunal (art. $403 \mathrm{del} C P C$ ), que hace prueba plena respecto de las circunstancias o hechos materiales que el tribunal establezca en el acta como resultado de su propia observación (art. 408 del CPC).

Queda por mencionar una cuestión conexa sobre la que conviene insistir, aunque el punto no formase parte de la discusión del caso. En materia procesal, no se debe confundir la "cosa pedida" con el "objeto material" del juicio, puesto que puede suceder que dos juicios tengan en común la cosa pedida y no el objeto material, y a la inversa que los objetos materiales sean idénticos, pero la cosa pedida sea diversa ${ }^{39}$. Solo en este segundo caso existe cosa juzgada (art. 177 del CPC). Esto significa que la configuración de la identidad de cosa pedida no supone un análisis meramente formal en el que se tenga en cuenta el objeto material en que consiste la pretensión, sino que ella se aprecia tomando en consideración los derechos alegados por la parte para efectos de poder acceder a ellos. De esto se sigue que no hay identidad en los casos en los que, si bien el resultado jurídico puede ser coincidente, este se consigue mediante el ejercicio de pretensiones diversas. En el juicio de reivindicación, la cosa pedida es el reconocimiento del dominio que tiene el actor sobre una cosa de la que no está posesión, para que se le restituya (art. 889 del $C C$ ). El objeto material sobre el que recae el beneficio jurídico cuya protección judicial se reclama es la parte del inmueble de la que el demandante se ha visto privado, que puede ser total o parcial. En el juicio comentado había también una cuestión registral discutida, porque el demandado sostuvo que el retazo

\footnotetext{
${ }^{39}$ Por ejemplo, la SCS 5 de mayo de 2016, rol núm. 2585-2015, CL/JUR/3053/2016, señala: "si se medita acerca de la cosa pedida en los dos procesos que se cotejan, se advertirá que, si bien las acciones incoadas se refieren al mismo objeto material, esto es, el cobro de pesos emanados del mutuo hipotecario que suscribieron, los derechos aducidos en una y otra son diversos" (cons. $9^{\circ}$ ). Del mismo modo, la SCA Santiago 20 de julio de 2001, rol núm. 6186-1997, CL/ JUR/197/2001; CL/JUR/5116/2001, dice: "Para que el beneficio jurídico sea el mismo no basta que sea idéntico el objeto material a que se refiere la cosa pedida, si el derecho que se pretende sobre ella fuere diverso" (cons. $8^{\circ}$ ).
} 
reclamado estaba dentro de los deslindes de su predio. Aunque esto no es un aspecto relevante, por el carácter extensivo que tiene el art. 915 del $C C$ del ámbito de aplicación de la acción reivindicatoria ${ }^{40}$, la decisión del asunto no comprometió el principio registral por el que se decanta el sistema chileno de propiedad raíz, que se ha popularizado con el nombre de "posesión inscrita": el demandado sí era actual poseedor (arts. 889 y 895 del CC), solo que la extensión territorial sobre la que ejercía un poder económico era distinta de aquella que le permitía la inscripción conservatoria existente a su nombre ${ }^{41}$.

\section{El proyecto de reforma del sistema registral y la delimitación de los linderos}

El 11 de septiembre de 2018, el Ministerio de Justicia y Derechos Humanos presentó un proyecto de reforma que moderniza el sistema notarial y registral en sus aspectos orgánicos y funcionales (Boletín núm. 12.092-07), el cual se encuentra hoy (20 de octubre de 2020) en discusión en el Senado ${ }^{42}$.

Uno de los aspectos que se modifican con esta reforma es el relativo al señalamiento de los deslindes de un predio, si bien el punto se aborda de una manera que es defectuosa y peligrosa. El proyecto ordena que todas las inscripciones futuras contengan

"la delimitación precisa [del inmueble] a través de las coordenadas expresadas en el sistema georreferenciado UTM o equivalente que determine el reglamento" (nuevo art. 78, núm. $2^{\circ}$ del RRCBR) ${ }^{43}$.

La exigencia no es menor si se considera que los deslindes no están expresados en la actualidad según medidas uniformes (y tampoco el proyecto prevé que así sea), y la fijación de las coordenadas UTM de sus vértices traerá consigo que la representación gráfica de la finca no coincidirá con aquella que existe en los registros a cargo del Conservador de Bienes Raíces. El resultado no es difícil de imaginar: las transferencias de predios modificarán en el texto de la inscripción los deslindes existentes en la práctica, de manera que el nuevo propietario podría ejercer una acción de demarcación para invadir el predio vecino fundado en el mérito de la inscripción (art. 842 del $C C$ ), que tiene un

${ }^{40}$ Alcalde (2019a), en especial pp. 173-179.

${ }^{41}$ Op. cit., pp. 173-175.

${ }^{42}$ Este proyecto ha sido analizado en Alcalde, Goldenberg (2019).

${ }^{43} \mathrm{El}$ sistema de coordenadas geográficas UTM se utiliza para referenciar cualquier punto de la superficie terrestre, empleando para ello un tipo particular de proyección cilíndrica que proyecta la Tierra sobre el plano. A diferencia del sistema de coordenadas geográficas, expresadas en grados que refieren la longitud y la latitud, las magnitudes en el sistema UTM se miden en metros. Cada cuadrícula UTM está señalada según el número del huso y la letra de la zona. Por ejemplo, de acuerdo con la información proporcionada por el Instituto Geográfico Militar, Santiago de Chile tiene las siguientes coordenadas UTM: norte: $6.340 .000 / 6.240 .000$ y este: 230.000/360.000. La ciudad se encuentra en el huso 19. 
carácter constitutivo (art. 686 del $C C$ ) y produce legitimación registral ${ }^{44}$. Todo, por cierto, sin una adecuada compensación económica para el afectado, lo que obliga a remitirse a las acciones de derecho común ${ }^{45}$.

Por cierto, el propio sistema de georreferenciación conforme a las coordenadas UTM presenta ya algunos inconvenientes. Entre los reparos más usuales que se le hacen se cuenta el que no existe una uniformidad en la escala de distancias; que ellas se agrandan a medida que se disparan del punto de tangencia esfera-cilindro en la dirección perpendicular al cilindro; que, en latitudes elevadas, a medida que el lugar de medición se aleja del punto de tangencia, la deformación es cada vez más significativa; que no se guarda proporción entre las superficies a diferentes latitudes; y que no se pueden representar las zonas polares o cercanas a ellos. Se trata de cuestiones que conviene tener en cuentan debido a la condición montañosa del país, su ubicación meridional dentro del hemisferio sur y su carácter sísmico.

El problema subyacente es que el proyecto mezcla cuestiones diversas que requieren de otros apoyos. El Registro inmobiliario contiene la representación jurídica de un inmueble, sobre el que el titular tiene ciertos derechos. La representación gráfica es propia de un catastro inmobiliario, vale decir, de un registro administrativo a cargo de un organismo público, donde se describen y valoran los bienes inmuebles rústicos, urbanos y de características especiales tal y como se definen en la ley, comprendiendo tanto el suelo como las construcciones ${ }^{46}$. La confección de un catastro general (porque los que hay en el país son parciales y para fines concretos) es una tarea que debe emprender el Estado, la cual ha de tener prioridad sobre el empeño de establecer el registro inmobiliario bajo un sistema de folio real ${ }^{47}$. Traspasar a los particulares la tarea de confeccionar planos individuales, como pretende el proyecto, va a provocar un sinnúmero de problemas, como aquel discutido en el caso que se ha comentado. Cabe esperar que ese defecto, que compromete de manera grave la seguridad jurídica, sea solucionado por el Senado y no se afecta la proyección física de las titularidades registrales ${ }^{48}$. Por lo demás, con la aplicación de tecnología a la gestión de los registros, en la actualidad la técnica del folio real, que el proyecto establece en paralelo al sistema de folio personal existente, carece de sentido, puesto que los mismos fines se pueden conseguir cruzando la información disponible. De hecho, varios conservadores del país ya lo hacen, ofreciendo una carpeta inmobiliaria del predio con toda la información disponible en sus registros.

${ }^{44}$ IBÁÑ̃EZ (2020).

${ }^{45}$ ZÚÑIGA (2020), en especial pp. 371-376.

${ }^{46}$ Muñoz (2016), p. 336.

${ }^{47}$ Alcalde (2019c). Tal era el diagnóstico de Pescio (1958), p. 367.

${ }^{48}$ En materia minera, por ejemplo, la superposición permite pedir la nulidad de una concesión (art. 95 del Código de Minería). La prescripción de esta acción trae consigo la extinción de aquella parte afectada por la superposición (art. 96 del Código de Minería). 


\section{CONCLUSiones}

En el caso analizado, la Corte Suprema resolvió el asunto de manera correcta y confirmó la decisión del tribunal de primera instancia, que había acogido la demanda de reivindicación respecto de un retazo de terreno cuya identificación provenía de un plano acompañado por el demandante y confeccionado conforme a los datos de la inscripción conservatoria y las mediciones hechas en terreno por un ingeniero agrimensor. Esto significaba que lo reclamado era la restitución de una porción de terreno que tenía unas determinadas medidas, que el demandado había anexado a su predio sin título alguno, conduciéndose respecto ella con ánimo de señor o dueño. La exigencia de singularizar el bien que se reivindica se satisface indicando cuál es su situación, sus linderos y la cabida, aunque esta puede presentar ciertas diferencias métricas que no comprometen la suerte de la acción.

La cuestión discutida sirve como una señal de alerta frente al proyecto de reforma al sistema registral en sus aspectos orgánicos y funcionales que se discute en el Senado. En este se prevé una nueva forma de indicar los deslindes de un predio, haciendo referencia a sus vértices según un parámetro de georreferenciación (sea en coordenadas UTM u otro mecanismo equivalente). Para ese efecto, se obliga al requirente de una nueva inscripción que confeccione a su costo un plano con la georreferenciación de su predio. Los problemas surgen porque, pese a indicarse el uso de esta manera de localizar los bienes raíces, no se exige que sus linderos se expresen de acuerdo con el sistema métrico decimal, que está vigente en Chile desde 1848. Además, la confección de planos se hace de manera individual y separada, lo que implica necesariamente que se producirán un sinnúmero de superposiciones prediales. Eso fue lo que sucedió en el caso aquí comentado, donde para el predio del demandado se había levantado un plano como parte de los trámites del procedimiento de regularización del DL 2695/1979. Una medida razonable es proceder a la conformación de un catastro inmobiliario general con los datos que ya existen, asumiendo un organismo administrativo los costos y tareas asociadas a su elaboración. De esta manera, el levantamiento cartográfico se hace por comunas, provincias y regiones, sin comprometer los derechos de los propietarios colindantes por la transferencia que pueda hacer un vecino.

\section{Bibliografía CITADA}

AlCalde Silva, Jaime (2019a). "La acción del artículo 915 CC es equivalente a la acción reivindicatoria propiamente tal, siendo competencia del tribunal efectuar la calificación sobre la forma en que el demandado ocupa el bien que se reclama. No resulta admisible la prescripción adquisitiva extraordinaria contra título inscrito. La acción reivindicatoria tiene por fin que la titularidad del dueño sea reconocida y se le restituya el bien que le pertenece. La fun- 
ción de la inscripción como prueba de la propiedad de un inmueble. Corte Suprema, sentencia de 29 de noviembre de 2018, rol núm. 41.935-2017 (CL/ JUR/6642/2018)". Revista Chilena de Derecho Privado, n. ${ }^{\circ} 32$.

AlCAlde Silva, Jaime (2016). "El saneamiento de la pequeña propiedad raíz. El sistema posesorio del Código Civil y el especial previsto por el DL 2695/1979. La interrupción civil de la prescripción. Momento a partir del cual se debe considerar que se ha producido el efecto interruptor de 'todo recurso judicial'. La notificación de la demanda como exigencia histórica y sistemática para que el dueño puede beneficiarse de dicha interrupción. Corte Suprema, sentencia de 31 de mayo de 2016 (rol núm. 6900-2015)". Revista Chilena de Derecho Privado, n. ${ }^{\circ} 27$.

AlCalde Silva, Jaime (2019b). "Notas para una relectura del sistema de la propiedad raíz en el Derecho chileno”, en Carmen Domínguez Hidalgo (ed.). Estudios sobre propiedad y posesión. Perspectiva chilena y latinoamericana. Santiago: Thomson Reuters.

Alcalde Silva, Jaime (2019c). "¿Y si se comienza por un catastro inmobiliario?”. Estado Diario, 20 de agosto de 2019. Disponible en https://estadodiario.com/ al-aire/y-si-se-comienza-por-un-catastro-inmobiliario/ [fecha de consulta: 15 de octubre de 2020].

Alcalde Silva, Jaime y Juan Luis Goldenberg Serrano (2019). "Algunas observaciones preliminares respecto del proyecto de ley que modifica el sistema notarial y registral en sus aspectos orgánicos y funcionales". Revista Chilena de Derecho Privado, n. ${ }^{\circ} 33$.

Corral Talciani, Hernán (2020). Curso de Derecho Civil. Bienes. Santiago: Thomson Reuters.

De Ramón, Armando y José Manuel Larraín (1979). "Una metrología colonial para Santiago de Chile: de la medida castellana al sistema métrico decimal”. Historia, vol. 14 .

Fuentes GuíñEz, Rodrigo (2020). "Acción demarcatoria y reivindicatoria: su confuso deslinde”, en Rodrigo Fuentes Guíñez y Valeska Opazo de la Fuente (eds.). El derecho de propiedad: estudios públicos y privados. Valencia: Tirant Lo Blanch.

Goldenberg Serrano, Juan Luis (2019). "Revisión de los mecanismos de protección de terceros en la regularización de la pequeña propiedad razón: una primera lectura de la Ley núm. 21.108”, en Carmen Domínguez Hidalgo (ed.). Estudios sobre propiedad y posesión. Perspectiva chilena y latinoamericana. Santiago: Thomson Reuters.

González Poveda, Pedro (2002). Acciones protectoras del dominio y de la posesión. Barcelona: Bosch.

GonzÁlez y Martínez, Jerónimo (2009). "El principio de publicidad”, en Luis Díez-Picazo y Ponce de León. Don Jerónimo González. Madrid: Colegio de Registradores de la Propiedad y Mercantiles de España.

GuZMán BRito, Alejandro (1995). Las cosas incorporales en la doctrina y en el derecho positivo. Santiago: Editorial Jurídica de Chile. 
IbÁÑEz LeÓn, Arturo (2020). “Cuidado con los deslindes”. El Mercurio Legal, 14 de enero de 2020. Disponible en www.elmercurio.com/Legal/Noticias/Opinion/2020/01/14/Cuidado-con-los-deslindes.aspx [fecha de consulta: 15 de octubre de 2020].

KIPER, Claudio (2010). Juicio de acciones reales. Buenos Aires: Hammurabi.

LAthrop Gómez, Fabiola (2011). "Diferencias entre la acción de demarcación y la acción de reivindicación. Comentario Sentencia Corte Suprema de 17 de agosto de 2010, rol núm. 5565-2010”. Revista de Derecho de la Escuela de Posgrado, n. ${ }^{\circ}$.

Mejías Alonzo, Claudia (2018). Derecho real de dominio y acción reivindicatoria. Posesión y acciones posesorias. Santiago. DER Ediciones.

Melo PARRA, Ignacio (2006). "Acción de demarcación y acción reivindicatoria: ámbito de aplicación". Revista de Derecho de la Universidad Católica de la Santísima Concepción, n. ${ }^{\circ} 14$.

Muñoz Machado, Santiago (ed.) (2016). Diccionario del español jurídico. Barcelona: Espasa.

Nino, Carlos Santiago (2014). Introducción al análisis del Derecho. $17^{\mathrm{a}}$ reimpresión de la $2^{\mathrm{a}}$ ed. Buenos Aires: Astrea.

Peñailillo Arévalo, Daniel (2019). Los bienes. La propiedady otros derechos reales. $2^{\mathrm{a}}$ ed. Santiago: Thomson Reuters.

Pescio Vargas, Victorio (1958). Manual de Derecho civil. Santiago: Editorial Jurídica de Chile, tomo IV.

Rabat Celis, Fernando y Francesca Mauriziano Concha (2011). "Algunas reflexiones acerca de la acción de demarcación”. Actualidad Jurídica, n. 24.

Rams Albesa, Joaquín, Rosa María Moreno Flórez y José Ignacio Rubio San Román (2020). Apuntes de Derecho inmobiliario registral, edición revisada. Madrid: Dykinson.

Sepúlveda Larroucau, Marco Antonio (2014). Teoría general del Derecho inmobiliario registral. Santiago: Metropolitana.

Vodanovic Haklicka, Antonio (2011). Tratado de los derechos reales. Reimpresión de la $6^{\text {a }}$ ed. Santiago: Editorial Jurídica de Chile.

VON BAR, Christian (2019). "Cuestiones fundamentales europeas del Derecho de posesión y del régimen jurídico negocial de las transmisiones en el Derecho de cosas". Anuario de Derecho Civil, tomo LXXII, fascículo III.

ZÁrate GonZÁlez, Santiago (2019). Tratado de Derecho inmobiliario registral. Santiago: Metropolitana.

ZúñIga Tejos, Álex (2020). "Calidad jurídica de un terreno ante la modificación unilateral de deslindes del fundo colindante: sistema de acciones", en Rodrigo Fuentes Guíñez y Valeska Opazo de la Fuente (eds.). El derecho de propiedad: estudios públicos y privados. Valencia: Tirant Lo Blanch. 


\section{Jurisprudencia citada}

SCS 5 de mayo de 2016, rol n. ${ }^{o}$ 2585-2015; CL/JUR/3053/2016.

SCS 23 de julio de 2014, rol n. ${ }^{\circ}$ 1755-2013; CL/JUR/4042/2014.

SCA Santiago 20 de julio de 2001 rol n. ${ }^{\circ}$ 6186-1997; CL/JUR/197/2001; CL/ JUR/5116/2001.

SigLAS Y ABREVIATURAS

art. artículo

arts. artículos

CC Código Civil

cons. considerando

CPC Código de Procedimiento Civil

CPR Constitución Política de la República

DL decreto ley

DS decreto supremo

ed. editora, edición

eds. editores

272

https HyperText Transfer Protocol Secure

$m$ metros

$\mathrm{m}^{2}$ metros cuadrados

n. ${ }^{\circ}$ a veces núm. número

op. cit. opere citato (obra citada)

p. página

pp. páginas

RRCBR Reglamento del Registro Conservatorio de Bienes Raíces

SCA Sentencia Corte de Apelaciones

SCS Sentencia de la Corte Suprema

Seremi Secretaría Regional Ministerial

UTM Universal Transversal de Mercator

wwww World Wide Web 